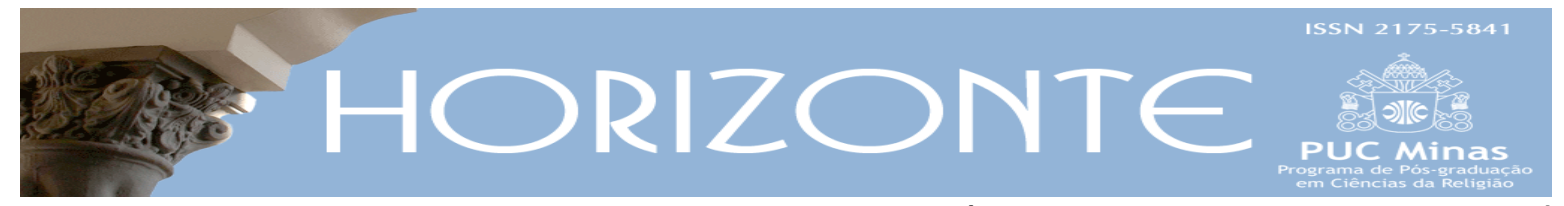

Temática Livre - Artigo original

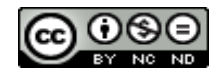

DOI - 10.5752/P.2175-5841.2014v12n34p932

\title{
A Teologia como ciência ôntica e sua relação com a Filosofia
}

\section{Theology as ontic science and its relation with Philosophy}

Paulo Sérgio Lopes Gonçalves *

\begin{abstract}
Resumo
Objetiva-se neste trabalho apresentar a teologia como ciência ôntica e sua relação com a filosofia ou "fenomenologia hermenêutica", conforme as contribuições de Martin Heidegger. Este objetivo se justifica mediante dois aspectos. O primeiro é o de explicitar a cientificidade da teologia no conjunto das ciências ônticas. O segundo é de romper com uma visão de que a filosofia é subserviente à teologia e apresentá-la como partner na condição de "fenomenologia hermenêutica". Para atingir este objetivo, tomar-se-á um conjunto de obras de Martin Heidegger que fundamentam sua filosofia ou "fenomenologia hermenêutica" presente em seu texto PhänomenologieundTheologie. Em seguida, apresentar-se-á a Teologia como ciência ôntica e sua relação com a filosofia. Disso resultará a concepção de ciência, a onticidade da teologia e seu caráter histórico, sistemático e prático. Emergirá também a função da filosofia como "corretivo ontológico" e a linguagem teológica com um pensar e um dizer abertos para existência ontológica da fé crista.
\end{abstract}

Palavras chaves:fenomenologia; hermenêutica; teologia; ciência ôntica.

\begin{abstract}
The article aims to present theology as ontic science and its relation with Philosophy or "hermeneutic philosophy", according the contributions of the philosopher Martin Heidegger. Such proposal justified in view of two aspects. The first one is to explain the scientific dimension of theology in the set of ontic sciences. The second is to break with that view that philosophy is subservient to theology and to present it as partner in the condition of a "hermeneutic phenomenology". To achieve this goal, we will take a set of works of Martin Heidegger that supports his philosophy or "hermeneutic phenomenology" which is present in his text Phänomenologie und Theologie. Then we will introduce Theology as ontic science and its relation to philosophy. The result will be the conception of science, the onticity of theology and its historical, systematic, and practical nature. In this sense, the function of philosophy will appear as "ontological corrective" and the theological language ash a sort of some thinking and talking open to ontological existence of the Christian faith.
\end{abstract}

Keywords: phenomenology; hermeneutical; theology; ontic science.

Artigo recebido em 15 de maio de 2014 e aprovado em 18 de setembro de 2014.

${ }^{*}$ Doutor em Teologia. Atualmente é Docente Pesquisador de Teologia e Diretor do Centro de Ciências Humanas e Sociais Aplicadas e avaliador institucional e de cursos de Filosofia e Teologia, do MEC-INEP. País de origem: Brasil. E-mail: paselogo@puc-campinas.edu.br. 


\section{Introdução}

O caráter científico da teologia pode ser afirmado, seja na concepção de Tomás de Aquino como scientia fidei, seja em seu caráter de sabedoria constituída de rigor metódico que conjuga fé e razão. Há também a possibilidade de contestar o caráter científico da teologia, atribuindo-lhe uma identidade de discurso religioso que, por vezes, está em contraposição ao discurso científico e por não se caracterizar como um complexo teórico a ser comprovado empiricamente. A era contemporânea está marcada por debates acerca da cientificidade da teologia, atribuindo à denominada virada hermenêutica, especialmente ocorrida com Martin Heidegger e apropriada por vários teólogos, a responsabilidade de possibilitar a construção da identidade científica da teologia e o diálogo com as ciências humanas, as ciências naturais e as ciências exatas. Supera-se então a ideia de uma teologia pura, isenta da mediação hermenêutica e da articulação com outras ciências para se constituir como complexo teológico. Formulou-se então uma teologia hermenêutica e uma hermenêutica teológica que trouxeram à tona a centralidade antropológica na elaboração teológica (GONÇALVES, 2011) e que também caracterizaram a teologia como ciência (LIBÂNIO, 2011). Mas que tipo de ciência é a teologia? Seria uma ciência semelhante às ciências da natureza ou às ciências exatas? Em sua consistência científica, a teologia deixou de ter a filosofia como partner ou ainda é a filosofia, fundamental para a constituição científica da teologia?

A busca de respostas a essas questões exige conceber como problema fundamental a cientificidade da teologia e sua relação com a filosofia. Para se defrontar com esse problema escolheu-se o texto de Martin Heidegger, intitulado "Fenomenologia e Teologia" - Phänomenologie und Theologie-, originário de Conferência ministrada aos o8 de julho de 1927 em Tübingen, repetida em Marburgo aos 14 de fevereiro de 1928 e publicado pela primeira vez nos Archives de Philosophie, vol. XXXII em 1969, junto com um apêndice, escrito em 1964, 
sobre "O problema de um pensar e dizer não objetivantes na teologia hoje" - Das Problem eines nicht objektivieren den Denkens und Sprechens in der heutigen Theologie - (HEIDEGGER, 1976a, p.68).

Justifica-se a escolha deste filósofo alemão o fato de sua filosofia ter incidido na teologia contemporânea, especialmente em teólogos como Rudolf Bultmann (1986) e Karl Rahner (1997). Por isso, objetiva-se neste artigo apresentar a cientificidade ôntica da teologia e sua relação com a filosofia, identificada como "fenomenologia hermenêutica" (STEIN, 2001, p. 61). Para atingir este objetivo, tomar-se-á o texto Phänomenologie und Theologie, interpretando sua estrutura em articulação com outros textos da época, principalmente com o espírito de Ser $e$ Tempo - Sein und Zeit (HEIDEGGER, 1977) - considerada obra fundamental de Martin Heidegger. Em seguida, afirmar-se-á a cientificidade ôntica da teologia, amparada na conceituação de ciência, sua relação com a filosofia apresentada como “corretivo ontológico” e a constituição da linguagem da teologia imbuída de um pensar e um dizer "não objetivantes”.

\section{Contextualização e estrutura do texto Phänomenologie und Theologie.}

O texto em referência surgiu em 1927, o mesmo ano em que Heidegger publicou a obra Sein und Zeit, cuja importância histórica no pensamento filosófico é fundamental. A publicação desta obra realizou-se em função de que para ocupar a cátedra deixada por Nicolai Hartmann em Marburgo para ocupar outra cátedra em Berlin, havia a necessidade que Heidegger publicasse uma obra originariamente sua que não fosse apenas as suas lições ministradas na Universidade (VON HERMANN, 1997, p. 30).

A produção de Sein und Zeit se contextualiza na "fenomenologia hermenêutica" da facticidade que Heidegger desenvolveu nos cursos sobre fenomenologia da vida religiosa em 1920-21 (HEIDEGGER, 1995) e sobre hermenêutica em 1923 (HEIDEGGER, 1982). Nesses cursos, o filósofo alemão 
mostrou-se simultaneamente influenciado pela fenomenologia transcendental de Edmund Husserl e capaz de mostrar que sua fenomenologia é hermenêutica. Além disso, explicitou também seu elo de relação com a teologia, constituído na década de 1910 quando estudou com jesuítas, obtendo formação teológica e filosófica medieval, tendo realizado um trabalho sobre Duns Scotto e um curso ministrado sobre mística medieval (MAC DOWELL, 1993, p. 23-39).

No primeiro curso, ao propor-se analisar o fenômeno religioso nas cartas paulinas, em Santo Agostinho e na mística medieval trouxe à tona o conceito de mundo em sua tripartição de mundo de si (selbstwelt), mundo dos outros (mitwelt) e mundo circundante (unwelt). Desenvolveu também o conceito de "experiência de vida fática" - faktische Lebenserfahrung - em que se realça o "como" se vive o que é experimentado na vida vivida. No segundo curso, Heidegger define a hermenêutica como o modo unitário de abordar, ter acesso, questionar e explicar a facticidade. Por isso, a hermenêutica concentra-se na vida, enquanto se manifesta como um todo aberto, dinâmico e passível de interpretação em função do dinamismo existencial do próprio homem. A despeito da distinção entre fenomenologia e hermenêutica, não se visualiza em Heidegger a separação destes dois elementos. Antes, ele conjuga a ambos a ponto de caracterizar sua fenomenologia como "fenomenologia hermenêutica":

Destacamos agora que o ser no modo de encobrir-se e o velar-se - e isto não acidentalmente senão por seu caráter-de-ser - é inerente ao caráterde-ser do ser que é objeto da filosofia, teremos então uma noção verdadeiramente rigorosa da categoria de fenômeno. A tarefa, portanto, de fazer dele fenômeno resulta ser aqui radicalmente fenomenológica. Esta via é a que pretende seguir a hermenêutica da faticidade (HEIDEGGER, 1982, p. 76).

O conceito de "fenomenologia hermenêutica" também está amparado em uma preocupação que Heidegger demonstrou ter em toda a sua vida: a preocupação com o ser, ou melhor, com a história do ser. Em sua concepção, teria sido tarefa da metafísica ter apresentado a história do ser, porém a metafísica 
ocidental apresentou somente a história do ente, desembocando na história do ente supremo e no esquecimento do ser. Ao ocupar-se com a questão em "como" trazer à tona o ser, Heidegger pôs-se a pensá-lo a partir da concepção de tempo, cuja expressão se encontra em sua obra "O conceito de tempo" - Der Begriff der Zeit(HEIDEGGER, 2004) que, conforme a designação de Thomas Sheehan (2007) é um primeiro esboço de Sein und Zeit. Tem-se então a experiência do homem no tempo da vida, tanto naquilo que lhe é dado quanto ao que ele constrói mediante suas decisões. No tempo, o homem faz a experiência da angústia, do medo, da tristeza, da alegria, da dádiva, da esperança, da finitude, confrontando-se com a morte e concebendo-a como encerramento de possibilidades e como horizonte ao qual ele se dirige. Ao possuir tal direção se sente interpelado a viver o tempo, na temporalidade tripartida: passado, presente e futuro - concentrando-se no "agora" em que necessita tomar suas decisões.

A obra Sein und Zeit é a espiritualidade do texto Phänomenologie und Theologie. Esta obra é a primeira publicação de Heidegger desprendida de cursos semestrais ou anuais e com um espírito investigativo, necessário para assumir a cátedra deixada por Nicolai Hartmann na Universidade de Marburgo. Exigia-se que a publicação tivesse em torno de 400 páginas, mas Heidegger tinha escrito em 1926 cerca de 534 páginas, compreendendo todo o projeto originário da primeira parte de Sein und Zeit, composto de três secções. Em carta a Jaspers, Heideger afirma ter as duas primeiras secções boa consistência filosófica, havendo necessidade de rever com maior cuidado a terceira parte (BIEMEL; SANER, 1990, p. 72). As duas primeiras secções referiam-se a pensar o ser no tempo, mediante a conceituação de ser-aí - Dasein - e sua relação com o tempo. Por isso, a primeira secção intitula-se “A interpretação do Ser-aí pela temporalidade e a explicação do tempo como horizonte transcendental da questão do ser" - Die interpretation des Daseins auf die Zeitlichkeit und die Explikation der Zeit als des transzendentalen Horizontes der Frage nach dem Sein - em que se conceitua fenomenologia, analítica existencial, cuidado, hermenêutica e círculo hermenêutico. Por sua vez, a segunda secção está intitulada "Ser-ai e temporalidade" - Dasein und Zeitlichekeit- explicitando o caráter prático de ser e tempo. 
A terceira secção teria sido projetada como "Tempo e ser" - Zeit und Sein- e não fora publicada porque o prazo para entregar a publicação que lhe proporcionaria condições para ocupar a cátedra de Hartmann, não permitia a devida correção. Por isso, o curso "Os problemas fundamentais da Fenomenologia” - Die Grundprobleme der Phänomenologie - (HEIDEGGER, 1999) ministrado em 1927, constitui-se em uma nova elaboração da terceira secção da primeira parte de Sein und Zeit. Trata-se de compreender o ser a partir do tempo - Zeit und Sein- o que explica a própria estrutura do curso: a apresentação das quatro teses sobre o ser, a questão ontológico-fundamental correspondente ao sentido do ser em geral, e o método científico e a ideia de fenomenologia. Por compor-se deste espírito de Zeit und Sein, é que este curso se tornou a primeira obra a ser publicada na coleção Gesamtausgabe.

Também em 1927, Heidegger ministrou um curso sobre a história da Filosofia (HEIDEGGER, 2009), em que abarcou três dos autores que são desenvolvidos em suas teses sobre o ser: Tomás de Aquino, Descartes e Kant. Neste texto, Heidegger possui um capítulo introdutório em que explicita a razão de partir de Tomás de Aquino: para formular uma ontologia fundamental, de conotação fenomenológico-hermenêutica visando efetuar seu projeto de destruição da metafísica, tem no Aquinate a expressão de uma metafísica que privilegiou o ente como natureza e como ente supremo - Deus - possibilitando que Descartes formulasse a questão do ser como res extensa e res cogitans, apresentando a matemática para a formulação de uma ontologia da natureza. Por sua vez, Kant formulou uma metafísica científica, de conotação transcendental em que a ideia é chamada de "o sumo de todas as possibilidades, prototypon transcendentale, protótipo transcendental, ideal transcendental” (HEIDEGGER, 2009, p. 14). Da ideia se salta para a determinação do ente em seu ser, cuja possibilidade se realiza em um modo de ser ou na "coisidade" que propicia que a coisa seja comparada com o "sumo de todos os predicados possíveis" (HEIDEGGER, 2009, p. 15). Deste modo, Heidegger assenta o seu conceito de ciência, em que se tem o aristotelismo trazido por Tomás de Aquino, o novo significado da matemática para analisar a 
natureza, fundamentando-se tanto em Descartes quanto em Leibniz, a metaphysica specialis de Kant, propiciando que se distinga ciência de filosofia. Com isso, tem-se a ciência como instância ôntica e a filosofia como instância ontológica, para que sejam pensados quatro problemas na investigação de seu curso: ser, natureza, homem, verdade (HEIDEGGER, 2009, p. 7-48).

A unidade de todas essas obras propicia que a questão do ser, de sua história e da análise de sua presença, traga à tona a distinção entre ciência e filosofia, a identificação entre filosofia, ontologia e fenomenologia, a vinculação entre fenomenologia e hermenêutica e a diferença ontológica entre ser e ente. Esta unidade é importante para que se compreenda que o conteúdo do texto Phänomenologie und Theologie se situa no contexto do próprio filosofar heideggeriano, em que se busca superar posições fechadas em determinadas sentenças.

O texto Phänomenologie und Theologie é sistemático e seu objetivo é conceituar a teologia como ciência ôntica e apontar a sua relação com a filosofia, marcada pela perspectiva ontológico-fenomenológica. Para isso, aponta suas fontes: os textos aqui expostos anteriormente, principalmente a obra Sein und Zeit para conceituar a fenomenologia, a primeira parte das "Considerações intempestivas" de Friedrich Nietzsche, referente ao "Esplêndido de Hördelin", e o opúsculo "Sobre o caráter cristão de nossa teologia de hoje" de Franz Overbeck. Em seguida retoma o conceito de ciência, explicando o seu caráter ôntico e sua positividade, situa a teologia como ciência ôntica, apontando a fé em Cristo como seu positum para descrevê-la como historiológica, sistemática e prática, e apresenta a filosofia como "corretivo ontológico" da teologia. Importa também ressaltar que Heidegger acrescentou em 1964 um apêndice em que confirma a exposição feita nas conferências de Tübingen e Marburgo, alude aos seus textos sobre Nietzsche em que é possível um conjunto de elementos para a teologia, especialmente a "morte de Deus" e também afirma "o dizer não objetivante da teologia", como maneira de retomar elementos da linguagem, considerada como importantíssima em toda obra de Heidegger, principalmente na "Carta sobre o 
Humanismo" -Brief der Humaninus- (HEIDEGGER, 1976b, p. 312-364) e sua conjugação com a experiência cotidiana, presente no conceito de experiência de vida fática.

\section{A teologia como ciência ôntica}

\subsection{A definição da ciência em sua onticidade}

Para caracterizar a teologia como ciência ôntica, Heidegger conceitua ciência como "o desvelamento fundante de uma região do ente ou do ser, cada vez mais fechada em si mesma, em virtude de ter sido desvelado" (HEIDEGGER, 1976a, p. 48). Cada região possui objetos que estão constituídos de um modo específico de possível desvelamento, demonstração, fundamentação e cunhagem de conceitos que dão forma ao conhecimento emergente. Em função desse conceito, a ciência é a possibilidade do Dasein que aponta para a relação da ciência com a existência do homem. Nessa relação, constata-se a existência pré-científica que, de certo modo, "pertence à existência científica em geral" e que "caracteriza positiva e primariamente essa existência" (HEIDEGGER, 2009, p. 26). Deste modo, Heidegger identifica existência pré-científia com o ser-estar-no-mundo, de modo que se retrata a maneira como os instrumentos se inserem no mundo público. Ao existir, a ciência toma um ente constituído de um positum como um tema previamente dado e desvelado antes mesmo do desvelamento científico (HEIDEGGER, 1976a, p. 48).

Ao analisar o ente em seu positum - a região a ser desvelada e imbuída de uma existência pré-científica - a ciência se caracteriza como positiva, pois reside na orientação diretiva da objetivação ao ente daquilo que se tornou tema, como umprogresso da postura pré-científica existente em relação a esse mesmo ente. Na positividade da ciência, Heidegger identifica a sua onticidade, constatando a possibilidade de encontrar algum ente já desvelado, em um âmbito tematicamente abrangente e passível de objetivação e questionamento teóricos. No entanto, 
Heidegger admite também a previedade do positium, enquanto é encontrado em um determinado modo pré-científico de acesso, cujo modo de lidar denota um caráter especificamente concreto desta região e o modo de ser do respectivo ente. Assim sendo, é intrínseco à positividade, o posicionamento pré-científico diante do ente presente já estar imbuído da iluminação e da condução por uma compreensão do ser, ainda que esta compreensão não seja provida conceitualmente. Isso possibilita e justifica a variação da positividade conforme o caráter concreto do ente, em consonância com o seu modo de ser, com o modo de realização do desvelamento pré-científico do ente correspondente e com o modo de pertença deste desvelamento ao que ali está previamente presente (HEIDEGGER, 1976a, p. 47-51).

Ao afirmar a previedade do positum, identificando-a com a existência précientífica, Heidegger busca superar uma concepção reducionista de ciência que se vale de um determinado objeto, descontextualizado de uma situação hermenêutica correspondente à existência do homem. Por isso, afirma ser a ciência a possibilidade de existência do Dasein, porque sua imersão é situada e acompanhada da pré-existência científica. A existência da ciência se efetiva em uma determinada região da coisa em causa, com seu modo de acesso próprio e com modos de mostrar e demonstrar a verdade.

\subsection{A ciência ontológica: a Filosofia}

Ao definir a ciência como ôntica em função de seu positum, Heidegger apresenta o outro tipo de ciência: a ontológica. Para ele, somente a filosofia possui caráter ontológico, por propor-se a pensar o ser de modo crítico. No entanto, este pensar não desvia o seu olhar do ente e nem perde aquele caráter de análise ônticaque é próprio da ciência. A análise filosófica se refere ao ente a partir de seu ser, compreendido na existência existenciária desse mesmo ente. Aqui se retorna o tema da diferença ontológica entre ser e ente (HEIDEGGER, 1999, p. 305-317) desenvolvida na relação entre tempo e ser, na qual irrompe o cumprimento do Dasein no tempo em sua temporalidade ek-stática e horizontal (VON HERMANN, 
1997, p. 55-57). Mas o caráter crítico da filosofia refere-se à sua profundidade ontológica e capacidade de distinguir fundamentalmente entre ser e ente e apontar o caminho do ser do ente (HEIDEGGER, 2009, p. 38).

Ao afirmar que a filosofia é ciência do ser, Heidegger a caracteriza como ontológica. Em seu caminho de “destruição da metafísica”, Heidegger elucidou em sua obra Beiträge zur Philosophie (Contribuições para a Filosofia) que a metafísica é como uma cadeia irremovível de montanhas e que sua "destruição" requer a construção de uma ontologia fundamental. Esta é a proposta de Sein und Zeit que se complementa em Grundprobleme der Phänomenologie e também em Beiträge zur Philosophie. No entanto esta ontologia fundamental se identificou com a fenomenologia, que por sua vez, já estava identificada com a hermenêutica. Por isso, a filosofia é para Heidegger o ato de filosofar ou o ato de pensar o fundamento identificado com a verdade e com o ser. O caráter desse filosofar é o de uma ontologia fenomenológica ou simplesmente uma "fenomenologia hermenêutica”.

A explicação de Heidegger para apresentar a sua ontologia fundamental de conotação fenomenológico-hermenêutica encontra-se no parágrafo 7 de Sein und Zeit. Para conceituar a fenomenologia, Heidegger parte da etimologia da palavra, defrontando-se com duas palavras gregas: phainomenon e logos. A primeira remete ao termo fenômeno, deriva do verbo phainesthai e significa aquilo que se manifesta. Mas é também infinitivo médio de phaino, cujo significado é trazer ao dia, pôr na luz, ou ainda, aquilo em que algo pode tornar-se visível em si mesmo. Por isso fenômeno é aquilo que se mostra em si mesmo, é o manifesto, é o que pode ser trazido à luz. Os gregos identificavam fenômeno com ta onta, que se traduz por ente. Com isso, entende-se que o ente pode mostrar-se a partir de si mesmo, de diversas maneiras, conforme o modo de acesso a ele. A partir dessa descrição, Heidegger distingue fenômeno de aparência, dando ao primeiro a conotação de sentido positivo e original de phainomenon e ao segundo a modificação privativa do fenômeno. Ao aprofundar essa distinção, o filósofo alemão apresenta outras 
duas distinções: o fenômeno índice e o fenômeno puro. $\mathrm{O}$ fenômeno índice possui quatro sentidos: ele é o anúncio daquilo que não se manifesta; é o anúncio identificado como fenômeno enquanto aquilo que, ao manifestar-se, indica o que não se manifesta; é a designação do sentido autêntico do fenômeno em sua condição de manifestação de si; é o próprio fenômeno puro. Este último sentido do fenômeno índice é já o fenômeno puro, enquanto é o anúncio de algo que surge do não manifesto e, por conseguinte, é aquilo que é essencialmente incapaz de manifestar-se. Ao debruçar-se sobre o logos, Heidegger o entende como o tornar manifesto aquilo que se discorre no discurso. O logos faz ver algo que discorreu. Por isso, o logos está relacionado à linguagem, pela qual algo se mostra a ser visto. Disso resulta, a relação entre logos e aletheia - no sentido de clareira - que possibilita pensar na relação entre velamento e desvelamento. O logos desvela sem deixar de velar, de ocultar e de visualizar a abertura já existente naquilo que foi desvelado (HEIDEGGER, 1977, p. 36-53). A partir do sentido dessas duas palavras, tem-se o sentido de fenomenologia: é aquilo que faz ver e se manifesta a partir de si mesmo.

Com essa definição, Heidegger tem a fenomenologia como método e identificada com a ontologia, assimilada em perspectiva da analítica existencial. Mediante a fenomenologia tem-se o acesso ao fenômeno que propicia ter acesso ao ser do ente, compreendido em sua existência ontológica e ôntica. Disso resulta a relevância do Dasein que é ponto crucial para analisar o ser, cuja compreensão não é possível sem incidir no ser do Dasein e sem penetrar sua existência. Ao realizar tal penetração, tem-se a necessidade de recorrer à hermenêutica, pois o hermenêutico é o elemento ontológico da compreensão à medida que ela se radica no existenciário da existência. Por isso, o Dasein é hermenêutico em si mesmo, enquanto é residência de uma pré-compreensão, fundamento do desenvolvimento de toda hermenêutica, especialmente do funcionamento do círculo de compreensão. O logos da fenomenologia do Dasein, a analítica existencial, é hermenêutico, porque anuncia a compreensão do ser, no interior desse mesmo Dasein (HEIDEGGER, 1977, p. 56-70). 
Em Sein und Zeit, Heidegger sofistica as implicações da hermenêutica em quatro funções: a explicitação, a elaboração das condições de possibilidade de toda análise ontológica, a realização da analítica do existenciário da existência e a efetuação da metodologia das ciências do espírito. Assim sendo, a "fenomenologia hermenêutica" explicita as estruturas existenciais do Dasein e orienta a atenção para o ser desse mesmo Dasein, pois o acesso ao ser só é possível mediante o horizonte de sua elucidação na existência do Dasein. Por isso, torna-se importante analisar a existência partir do tempo, compreendido na temporalidade da existência do Dasein, da sua historicidade, na qual o ser dá-se na verdade à medida que experimenta a angústia, o medo, a necessidade e a capacidade de decidir, e a morte. Dessa forma, a verdade está toda relacionada ao Dasein que se abre ao ser da verdade. Nessa abertura, a linguagem se revela mais ampla do que simples proposições de ordens e sentenças, e abarca o discurso - Rede - como sua forma básica, apesar de não ser a única. A linguagem possibilita a multiplicidade de significados, a abertura do Dasein ao mundo, emergindo dessa abertura a verdade enquanto desvelamento do que está velado (HEIDEGGER, 1977, p. 71-96). Neste sentido, a verdade não se fixa em uma determinada formulação, mas floresce do pensamento que está a caminho, emergente próprio processo de pensar e que simultaneamente pode ocultar e desocultar, encobrir e descobrir. O homem, o Dasein, é o mensageiro que se atém à solicitação hermenêutica do ser e que se coloca a serviço da manifestação desse mesmo ser, que enquanto fenômeno acontece como velamento e desvelamento (STEIN, 2001, p. 185-200).

\subsection{A positividade da teologia}

Da caracterização de ciência ôntica, Heidegger compreende a inserção da teologia no conjunto das ciências ônticas, pois possui um positum que lhe é previamente dado: a fé em Cristo, concebida como "cristicidade" - Christlichkeit(HEIDEGGER, 1976a, p. 52) assumida como um modo de existência do Dasein humano que acolheu o ente que lhe foi revelado, o Cristo. Deste modo, Heidegger 
afirma a confessionalidade da teologia e a centralidade cristã de sua exposição. Com isso, possibilita pensar o caráter proposital da exclusão do antigo testamento, por se tratar de um testamento judaico, símbolo do povo judeu, alvo da Alemanha que aderiu ao nazismo (CAPELLE, 2012, p. 22-25).

Utilizando-se de Overbeck, teólogo de inspiração luterana, como sua fonte, Heidegger afirma a cristicidade a partir do cristianismo primitivo presente em São Paulo - e aqui reside a importância de sua hermenêutica da experiência de vida fática realizada na análise fenomenológica da religião em algumas cartas paulinas e no período patrístico, em que Overbeck visualiza uma dupla antinomia. De um lado, se verifica uma determinação crística das comunidades cristãs - por exemplo com Clemente de Alexandria e Orígenes - e de outro se constata a influência da conceituação estrangeira, grega e latina. Esta antinomia se transformou pelo próprio autor na ótica escatológica do cristianismo primitivo em que se espera pela Parusia - a segunda vinda de Cristo - e na probabilidade de um cristianismo histórico fundamentado em sucessivas adaptações culturais da fé cristã.

A perspectiva deixada por Overbeck possibilitou que Heidegger ao afirmar a “cristicidade" apresentasse a relação do Dasein humano com o Cristo como uma relação de fé, imbuída de história, porque o próprio Cristo - deus crucificado aponta para um evento histórico testemunhado na Escritura. A historicidade deste testemunho está relacionada tão somente à fé e na fé, sem a qual nada se sabe deste fato. Transmitido pela fé, Cristo é então direcionado ao homem - Dasein - que, conforme o modo de ser que o permite existir recepciona a comunicação daquele Cristo crucificado. Essa transmissão não é uma comunicação pura de conhecimentos metafísicos efetivados em doutrinas e dogmas, mas o sentido existencial da própria fé: “o renascimento do homem” (HEIDEGGER, 1976a, p. 55). Por isso, a fé tem consistência no ato de crer, sendo sua realização a existência de credulidade no interior da história em que o evento da revelação aconteceu e foi apropriado por essa mesma fé. Ora, o todo do ente desvelado pela fé e o pertencer da fé ao nexo do acontecer desse mesmo ente, constituem a positividade da teologia. Dessa forma, a teologia cumpre o seu encargo a partir e em favor da fé e, 
ao tematizá-la com aquilo que é desvelado, possui o que é revelado. A fé é então, aquilo que entra na própria teologia, como tematização que abarca o todo do ente desvelado - o evento revelado - que deve ser zelado pela teologia em seu desenvolvimento como ciência ôntica (HEIDEGGER, 1976a, p. 51-55).

Ao compreender a positividade da teologia, Heidegger afirma também sua cientificidade (HEIDEGGER, 1976a, pp. 55-61) caracterizando-a não como uma ciência de fé, mas como "uma ciência em nome da fé" (CAPELLE, 2012, p. 23) e, por conseguinte, daquilo que é desvelado na fé, enquanto é aquilo que se crê. Por isso, a teologia é uma ciência do comportamento crente, que brota da fé, é motivada e justificada pela fé. A credulidade é também conformada em relação ao Cristo crucificado, recordando então a teologia da cruz elaborada na perspectiva luterana. Neste sentido, Cristo medeia a relação entre a fé e a cruz, propiciando que o crente afirme a sua fé no Cristo crucificado. Esta fé é o positum da teologia, enquanto é um modo do Dasein histórico desvelado somente na fé e para a fé. Aqui está o caráter ôntico da teologia e consequentemente a explicação para que Heidegger aproxime a teologia mais das outras ciências do que da filosofia: "Sem mais, desta tese resulta que a teologia, enquanto ciência positiva está por princípio mais próxima da química e da matemática do que da filosofia” (HEIDEGGER, 1976a, p. 49).

\subsection{O caráter historiológico, sistemático e prático da teologia}

Conforme a designação heideggeriana, em função do caráter histórico do Dasein, a teologia é uma ciência historiológica à medida que sua finalidade é a existência cristã realizada concretamente e não composta em um sistema. A objetividade da teologia está então, em clarificar a existência cristã, enquanto seja existência histórica, apontando para as possibilidades de existência de vida que o crente possui mediante a fé. Além disso, o realce ao caráter historiológico da 
teologia corresponde à exegese bíblica, à história da Igreja - principalmente a da comunidade primitiva - e a história do dogma - especialmente até Santo Agostinho - conforme a designação que já havia sido feita por Overbeck. Deste modo, tem-se aqui a afirmação da perspectiva protestante de fazer teologia, predominante na Alemanha da época de Heidegger. No entanto, a preocupação de Heidegger é com a cientificidade da teologia, o que lhe permite afirmar que se essas disciplinas devem representar uma "teologia autêntica e não âmbitos estranhos das ciências historiológicas, gerais e profanas, então elas devem deixar que a teologia sistemática, compreendida de modo reto, lhes prescreva qual é o seu objeto contraposto" (HEIDEGGER, 1976a, p. 58).

Ao afirmar que a teologia é uma ciência historiológica, Heidegger desemboca no caráter sistemático e prático da teologia. A positividade da teologia, concentrada na existência cristã que encontra o seu sentido na fé, propicia que seja sistematizado e organizado metodicamente o conteúdo historicamente emergente da experiência originária da fé, desdobrada historicamente em função do sentido da própria existência cristã, enquanto é credulidade do crente, de modo a dar consistência ao positum, garantindo assim sua cientificidade. No entanto, esta sistematização não se identifica com a ideia tradicional de sistema, enquanto corporifica um conjunto de doutrinas dogmáticas, morais e espirituais. O caráter sistemático está no fato de que aquele conteúdo originário ganhou historicidade e significado na existência do crente situado historicamente. Por isso, a teologia não abdica da história para ser sistemática, ao contrário, quanto mais historiológica consistir a teologia, mais sistemática será. Seu êxito está fundamentalmente em estabelecer os nexos históricos em seu objeto - o existir cristão - sem incidir em sistemas fechados. Consiste também esse êxito em ser sistemática mediante uma metodologia que acolha a historicidade da credulidade do crente e sua capacidade de recepcionar pela fé aquilo que a própria fé revelou.

A legitimidade da afirmação de que a teologia é também uma ciência prática está no fato de que o seu positum não é abstrato e nem incide em elucubrações abstratas. O seu positum, enquanto fé do crente é a fé em um acontecer 
existencialmente cristão, um evento revelado e recepcionado pela fé, um agir de Deus sobre o homem que age pela fé. Então, enquanto ciência prática, a teologia constata que Deus age falando ao homem, que por sua vez, guiado pela fé, organiza esta palavra que lhe é dirigida, transformando-a em homilética e catequética. A homilética corresponde à própria natureza da palavra de Deus dirigida ao homem, que encontra na liturgia cristã, um lócus specialis, no qual a palavra se vincula ao mistério cristão e à sua revelação. A catequética é palavra de Deus, revelada em Cristo e ensinada aos homens. Assim sendo a teologia prática é homilética e catequética não porque há necessidade de auxiliar na clarificação do conteúdo da fé cristã, mas porque o caráter prático da teologia se constitui como tal em sua organização fática. A homilética e a catequética realçam que a teologia é palavra de Deus que incide sobre a vida do homem, é acontecimento que interpela o homem à conversão, à adesão e à vivência da fé em seus nexos existenciais.

O caráter prático da teologia não se desvincula do caráter sistemático e nem do caráter historiológico. Os três caracteres estão entrelaçados: “a teologia só é historiológica se for sistemático-prática; só é sistemática se for prático-historial e só é prática se for historiológico-sistemática” (HEIDEGGER, 1976a, p. 59). Neste sentido, verifica-se a proximidade desta posição de Heidegger com o teólogo Rudolf Bultmann, seu colega de trabalho e amigo em Marburgo. Este teólogo confessou que se utilizou da filosofia de Heidegger na construção de sua teologia kerygmática existencial, fazendo uso da exegese bíblica e da história do cristianismo primitivo em correlação com os desafios que a fé enfrenta na era contemporânea (BULTMANN, 1986, p. 841). Com isso, a teologia é a palavra de Deus em linguagem humana, de interpelação para que o homem decida pela fé em sua existência e tenha uma existência autêntica na fé. É a esta autenticidade de fé que a teologia deve corresponder (BULTMANN, 1986, p. 287-312).

A simultânea unidade e multiplicidade das áreas teológicas não significa que a investigação teológica tenha uma conotação cognitiva meramente especulativa. A teologia não é um conhecimento especulativo sobre Deus, porque Deus não é um 
objeto de especulação, conforme possuem outras ciências ônticas o respectivo objeto passível de especulação (HEIDEGGER, 1976a, p. 59). Se Deus for tomado como objeto de especulação, então se produzirá teodicéia e não teologia. Também a teologia não é uma ciência do homem e seu modo de experimentar Deus, como se Deus fosse algo da psiché humana que possibilita a formulação de uma psicologia da religião. Nem tampouco, a teologia toma Deus como um objeto de especulação histórica ou sociológica ou antropológica, pois a teologia não é uma ciência da religião e nem se constitui em ciências da religião (GRESCHAT, 2006, p. 155-156). Ao falar de Deus, a teologia o faz mediante a fé que histórica e existencialmente possibilita o desvelamento histórico desse mesmo Deus ao homem. Ao recepcionar esse Deus que se desvela historicamente, o homem dá sentido cristão à sua existência. Dessa forma, a teologia não depende de outras ciências para apresentarse como científica. Ela é uma ciência ôntica autônoma, que se fundamenta primeiramente na fé e que possui sua própria especificidade a ponto de ser ela mesma a origem de seus conceitos. Sua objetividade está na própria fé que nela se origina e para ela retorna. No entanto, sua histórica relação com a filosofia denominada aqui de "fenomenologia hermenêutica", leva-nos a perguntar sobre a função da filosofia, na efetividade científica da teologia.

\section{A relação entre filosofia e teologia}

\subsection{A filosofia como "corretivo ontológico"}

Heidegger aponta a necessidade da relação entre filosofia e teologia para auxiliar a assegurar a cientificidade ôntica da teologia (HEIDEGGER, 1976a, p. 61). No entanto, a filosofia não serve para fundamentar cientificamente a teologia, porque essa fundamentação cabe à própria teologia. Entretanto, a filosofia serve para manifestar à teologia a possibilidade de firmar-se como ciência ôntica em seu positum e demonstrar o que é próprio de sua identidade, cujo desenvolvimento não se efetiva sem o solo da filosofia ou "ontologia fenomenológica" ou "fenomenologia 
hermenêutica”. Dessa forma, a explicitação conceitual a ser feita pela teologia acerca de seu positum deve apresentar o direcionamento relativo ao nexo ontológico em sua totalidade originária, mantendo-o permanentemente sob o seu foco.

O nexo a ser feito se situa no âmbito ontológico da existência, cuja consequência é a necessidade em considerar na onticidade da teologia, a previedade existencial da credulidade do crente. Justifica-se esta posição que a fé o positum da teologia - possibilita superar a existência pré-cristã, cujo Dasein implicado nessa fé possui nexo ontológico-existencial com a sua existência précristã. Esta ideia de superação não corresponde à supressão, mas à elevação que implica em co-pertinência da existência pré-cristã com a cristã. Dessa forma, a compreensão da fé a ser feita pela teologia não se desvincula da previedade existencial cristã do Dasein. Caso contrário, a teologia estaria apresentando seu positum sem o nexo ontológico existencial do Dasein implicado, incorrendo na possibilidade de elaborar seus conceitos fundamentais com isenção de existência ontológica. Isso faria da teologia uma ciência de sentenças fechadas, isentas de operação hermenêutica, porque não haveria a consideração histórico-existencial do Dasein que nela estaria implicado.

Heidegger exemplifica o que filosoficamente afirma relacionando o tema do pecado com o da culpa (HEIDEGGER, 1976a, p.63-64). Pecado é um conceito teológico, com maior desenvolvimento no âmbito da antropologia teológica e da teologia moral, mas seu nexo ontológico se situa na culpa. Esta não é um conceito teológico e nem é preciso dela para se afirmar o pecado. No entanto, o caráter teológico do reconhecimento do pecado possui previedade na culpa (HEIDEGGER, 1977, p. 374-376), que por sua vez, é "uma determinação existencial do Dasein, determinação originária e ontológica” (HEIDEGGER, 1976a, p. 64).

Ora, se há uma determinação originária e ontológica do Dasein para a teologia, cujo constitutivum essencial é a fé ou o renascimento, então na 
compreensão heideggeriana, a filosofia serve como "corretivo ontológico" (HEIDEGGER, 1976a, p. 65), sem que isso signifique sua superioridade em relação à teologia. Trata-se de um acompanhamento orientador para que a teologia esteja concentrada em seu positum e se apresente como ciência ôntica. Deste modo, a filosofia é partner da teologia que a orienta para a concentração em seu positum e sua consistência ôntica (HEIDEGGER, 1976a, p. 65-67).

Esta parceria entre filosofia e teologia não significa que ambas não podem se contrariar uma a outra, abandonando o que é próprio de cada uma. Importa então ressaltar a possibilidade de contraposição em função da contraposição entre a credulidade e a livre auto-assunção do Dasein. No entanto, essa contraposição não impossibilita a comunicação entre ambas, porque possibilita salvaguardar a identidade de cada uma, não sendo admissível uma "filosofia cristã" ou uma teologia de nominação filosófica. Esta comunicação se efetiva também no interior da própria teologia à medida que em sua problemática, gerada a partir de sua reflexão positiva acerca dos nexos ônticos de sua região, houver o confronto entre os conceitos fundamentais da teologia com a filosofia, e quando se tornar problemática a adequação entre os conceitos fundamentais hauridos da própria tradição e o ente tematizado. Então, a partir das exigências próprias da teologia e no limiar de seus conceitos fundamentais, torna-se possível perguntar pela constituição originária do ser do ente que deve continuar sendo seu objeto e tornarse novo, efetivando-se na ultrapassagem metodológica que propicia o acesso e a determinação ontológica. Neste sentido, a comunicação se torna autêntica à medida que há o questionamento mútuo entre filosofia e teologia, expresso de forma ôntico-positiva e ontológico-transcendental ou fenomenológicohermenêutica, guiado pela cientificidade em relação ao escopo de cada ciência e pela proximidade dialógica para suprir as necessidades da problemática científica.

\subsection{A linguagem da teologia em sua onticidade própria}

No apêndice supra mencionado do texto Phänomenologie und Theologie, Heidegger se preocupa em apresentar a linguagem da teologia, distinguindo-a 
claramente da onticidade da linguagem das ciências naturais. Ocupa-se então com a linguagem que exprime o pensar e o dizer que são próprios da teologia, o significado da objetivação, a relação entre pensar e dizer, e a objetivação ou não do pensar e do dizer.

Este apêndice foi escrito no contexto diferente do conjunto do texto, pelo fato de Heidegger ter amadurecido a concepção de Ereignis - Acontecimentoapropriativo -, manifestada especialmente na obra Beiträge zur Philosophie e na Brief über den Humanismus (VATTIMO, 2004). Seus desdobramentos estão em seus Ensaios e Conferências - Vorträge und Aufsätze - escritos na década de 1950 (HEIDEGGER, 2002) e na obra $O$ que significa pensar?-Was heisst denken? escrita em 1959 (HEIDEGGER, 2005). Heidegger apresenta de um lado, o dar-se do ser ao homem e de outro, a abertura do homem para recepcionar o ser. Nesta abertura, advém ao homem a linguagem para que ele elabore signos e fonemas que expressem este encontro com o ser, denominado de "Acontecimento-apropriativo". Por isso, a linguagem é concebida como a "casa do ser" (HEIDEGGER, 1976b, p. 361) e o homem o "pastor do ser" (HEIDEGGER, 1976b, p. 331) que habita esta casa. Disso resulta a relevância do cuidado para tratar da linguagem que contém o pensar que trabalha para construir a casa do ser, cuja habitação do ser é a "essência do ser-no-mundo" (HEIDEGGER, 1976b, p. 358). O pensar é "pensar do ser" convocado pelo ser em seu advento e, por conseguinte, a relação do ser com o pensar é destino. Por isso, o ser é, enquanto é destino do próprio pensar.

A concepção de linguagem como a "casa do ser” possibilita afirmar sua ultrapassagem da racionalidade expressa nas ciências naturais, quando se apresenta o fato comprovado cientificamente. A linguagem é mistério e fenômeno originário vislumbrado na experiência de abertura do homem ao seu advento. Disso resulta que o pensar a se manifestar na linguagem, não se reduz à racionalidade originada da empiria científica que apresenta resultados comprovados acerca dos objetos investigados (HEIDEGGER, 1976a, p. 71-72). 
Conforme o exposto, a linguagem teológica deve exprimir o seu pensar e o seu dizer de modo próprio e diferente daquele expresso na linguagem das ciências naturais. Por isso, a concepção de objeto em teologia não se refere à ideia de “objeto contraposto existente da experiência da ciência natural” (HEIDEGGER, 1976a, p. 73), mas da experiência humana das coisas que não é nem a coisa em si e nem o objeto contraposto. Aqui entra em jogo o pensar não necessariamente como representação, mas como postura acerca do que se mostra e como se mostra, para dizer aquilo que aparece. Pensar não é um mero raciocinar a partir de bases empíricas, mas meditar criticamente abarcando o todo do que deve ser mostrado. Nesta mesma perspectiva encontra-se o dizer, cujo escopo não é a realização da mera verbalização de signos e fonemas, mas o de exprimir o pensar que serve o ser, que é o “destino do ser”. O dizer deve então mostrar o que escuta do próprio pensar, pois tendo origem no pensar meditativo, se apresenta como um dizer pensante. Disso resulta que o dizer há de pronunciar as palavras com cuidado e sobriedade para designar a linguagem em que habita o ser (HEIDEGGER, 2005, p. 203-233).

Ora se o dizer deve exprimir o pensar meditativo, então a linguagem teológica jamais poderá ser técnico-científica no mesmo sentido da linguagem das ciências naturais, pois “teologia não é ciência da natureza” (HEIDEGGER, 1976a, p.

77). Assim sendo e considerando a cientificidade ôntica da teologia, urge a tarefa da teologia em constituir-se de uma linguagem que exprima o que pensa e como diz o que pensa, levando a cabo o seu positum, a fé cristã. Sua linguagem então não será aquela do cálculo matemático, mas a do pensar meditativo sobre o ser que repousa em sua casa. A meditação abre o pensar sobre o positum situado em cada época histórica, possibilitando que o dizer linguístico seja contemporâneo à existência do homem. 


\section{Conclusão}

Ao longo deste trabalho, objetivou-se apresentar a teologia concebida como ciência ôntica e sua relação com a filosofia. A motivação subjacente a este objetivo é a afirmação do caráter científico da teologia, cuja contemporaneidade muito se deve à filosofia. Para atingir este objetivo, tomou-se Martin Heidegger, renomado filósofo contemporâneo, como fonte principal de todo trabalho, particularmente o seu texto Phänomenologie und Theologie que se situa no contexto literário que abarca outras obras do autor, principalmente Sein und Zeit, para inferir o conceito de filosofia como "ontologia fenomenológica" ou como "fenomenologia hermenêutica" e de teologia como ciência ôntica. Em seguida, buscou-se refletir as contribuições da filosofia à afirmação da teologia como ciência ôntica.

Constata-se que Heidegger escreveu o texto supra mencionado em um horizonte hermenêutico vasto, com centralidade na obra Sein und Zeit e toda a problemática que a envolve originariamente. Por isso, buscou-se compreender o texto Phänomenologie und Theologie no contexto da hermenêutica faticidade e da ontologia fenomenológico-hermenêutica ou simplesmente "fenomenologia hermenêutica”. Deste modo, tornou-se possível compreender que Heidegger identifica a filosofia com a ontologia e esta com a fenomenologia de conotação hermenêutica, diferenciando-a da fenomenologia transcendental de Husserl.

A problemática fundamental do texto é a cientificidade ôntica da teologia e sua relação com a filosofia. Para pensá-la, Heidegger define a ciência em dois tipos: o ôntico e o ontológico. No ôntico situa a ideia de positum que possibilita pensar a região do ente a ser investigada em correlação com a previedade pré-científica desse mesmo ente. No ontológico situa a filosofia, cuja função é pensar o ser. Ao caracterizar a teologia como ciência ôntica, Heidegger visualizou o positium da teologia: a cristicidade ou a fé no Cristo crucificado. Isso significa que a teologia pensa a fé no Cristo crucificado, exigindo credulidade do crente para ser realizada como ciência. Ao apropriar-se da credulidade do crente, o teólogo sistematiza o 
positium de modo a desenvolver elementos da historicidade e do caráter prático da fé pensada. Por isso, a caracterização científica da teologia se efetiva por ser sistemática, historiológica e prática, objetivando conservar-se fiel em seu positium. Disso resulta a sua relação com a filosofia cujo espírito é de "ontologia fenomenológica" ou de "fenomenologia hermenêutica", para dar à teologia uma orientação ontológica que contribui para que o discurso teológico se mantenha em seu positum.

Ao apropriar-se da filosofia, a teologia garante sua cientificidade ôntica, não por ter elementos de comprovação empírica de sua verdade, mas por apresentar a verdade como abertura e por possuir uma linguagem que não se enquadra em sistemas fechados e encerrados em determinadas formas isentas de vivacidade. Assim, a teologia não precisará estar em contraponto com outras ciências e tampouco renunciar à filosofia em função da laicidade desta, temendo seu enfraquecimento e sua possível perda de espaço sagrado. Ao contrário, a teologia se consolidará como ciência ôntica por assumir sua identidade de fé cristã, constituída de existência humana, podendo melhor falar de Deus, porque sua linguagem estará cada vez mais aberta ao novum desse mesmo Deus.

\section{REFERÊNCIAS}

BIEMEL, Walter; SANER, Hans. (Org.). M. Heidegger und K. Jaspers: Briefwechsel 1920-1963. Fankfurt am Main; München; Zürich: Vittorio Klostermann; Piper, 1990.

BULTMANN, Rudolf. Credere e comprendere. Brescia: Queriniana, 1986.

CAPELLE, Philippe. Philosophie et Théologie dans la pensée de Martin

Heidegger. Paris: Cerf, 2012.

GONÇALVES, Paulo Sérgio Lopes. A identidade da teologia no estudo da religião. Revista Eclesiástica Brasileira, Petrópolis, v. 71, n. 281, p. 16-46, 2011.

GRESCHAT, Hans-Jürgen. O que é Ciência da Religião. São Paulo: Paulinas, 2006.

HEIDEGGER, Martin. Sein und Zeit. Gesamtausgabe 2. Frankfurt am Main: Vittorio Klostermann, 1977. 
HEIDEGGER, Martin. Brief über den Humanismus. In: HEIDEGGER, Martin.

Wegmarken. Gesamtausgabe 9. Frankfurt am Main: Vittorio Klostermann, 1976b. p. 313365 .

HEIDEGGER, Martin. Der Begriff der Zeit. Gesamtausgabe 64. Frankfurt am Main: Vittorio Klostermann, 2004.

HEIDEGGER, Martin. Phänomenologie des Religiösen Lebens. Gesamtaugsbe 60. Frankfurt am Main: Vittorio Klostermann, 1995.

HEIDEGGER, Martin. Phänomenologie und Theologie. In: HEIDEGGER, Martin . Wegmarken. Gesamtausgabe 9. Frankfurt am Main: Vittorio Klostermann, 1976a. p. 4578 .

HEIDEGGER, Martin. I problemi fondamentali della fenomenologia. Genova: Il nuovo Melangolo, 1999.

HEIDEGGER, Martin. História da Filosofia: De Tomás de Aquino a Kant. Petrópolis: Vozes, 2009.

HEIDEGGER, Martin. Ontologie. Hermeneutik der Faktizität. Gesamtausgabe 63. Frankfurt am Main: Vittorio Klostermann, 1982.

HEIDEGGER, Martin. ¿Qué significa pensar? Madrid: Trotta, 2005.

HEIDEGGER, Martin. Ensaios e Conferências. Petrópolis: Vozes; Bragança Paulista: São Francisco, 2002.

LIBANIO, João Batista. Teologia e Ciência. Revista Eclesiástica Brasileira, Petrópolis, v. 71, n. 281, p. 4-16, 2011.

MAC DOWELL, João. A gênese da ontologia fundamental de M. Heidegger. São Paulo: Loyola, 1993.

RAHNER, Karl. Hörer des Wortes. Schriften zur Religionsphilosophie und Grundlegung der Theologie. Sämtliche Werke 4. Düsseldorf: Benziger; Freiburg: Herder, 1997.

SHEEHAN, Thomas. Becoming Heidegeer: On the Trail of his Early Occasional Writtings, 1910-1927. Seattle: Noesis Press, 2007.

STEIN, Ernildo. Compreensão e finitude: Estrutura e movimento da interrogação heideggeriana. Ijuí: Editora Unijuí, 2001.

VATTIMO, Gianni. Depois da Cristandade: Por um Cristianismo não religioso. Rio de Janeiro; São Paulo: Record, 2004. 
VON HERMANN, Friedrich Wilhelm. La segunda mitad de Ser y Tiempo. Trotta: Madrid, 1997.

VON HERMANN, Friedrich Wilhelm. Die Metaphysik im Denken Heideggers. Edição alemã e tradução italiana de AncietoMolinaro: La metafisica nel pensiero de Heidegger. Città del Vaticano: Urbaniana, 2004. 